\title{
MESENCHYMAL STEM CELL RECRUITMENT BY STROMAL DERIVED FACTOR-1-DELIVERY SYSTEMS BASED ON CHITOSAN/POLY $(\gamma$-GLUTAMIC ACID) POLYELECTROLYTE COMPLEXES
}

\author{
Raquel M. Gonçalves ${ }^{1, *}$, Joana C. Antunes ${ }^{1,2}$ and Mário A. Barbosa ${ }^{1,2,3}$ \\ ${ }^{1}$ INEB - Instituto de Engenharia Biomédica, Universidade do Porto, Rua do Campo Alegre, 823, \\ 4150-180 Porto, Portugal \\ ${ }^{2}$ Universidade do Porto, Faculdade de Engenharia, Porto, Portugal \\ ${ }^{3}$ Universidade do Porto, Instituto de Ciências Biomédicas Abel Salazar, Porto, Portugal
}

\begin{abstract}
Human mesenchymal stem cells (hMSCs) have an enormous potential for tissue engineering and cell-based therapies. With a potential of differentiation into multiple lineages and immune-suppression, these cells play a key role in tissue remodelling and regeneration.

Here a method of hMSC recruitment is described, based on the incorporation of a chemokine in Chitosan $(\mathrm{Ch}) /$ Poly $(\gamma$-glutamic acid) ( $\gamma$-PGA) complexes. Ch is a nontoxic, cationic polysaccharide widely investigated. $\gamma$-PGA is a hydrophilic, non-toxic, biodegradable and negatively charged poly-amino acid. Ch and $\gamma$-PGA, being oppositely charged, can be combined through electrostatic interactions. These biocompatible structures can be used as carriers for active substances and can be easily modulated in order to control the delivery of drugs, proteins, DNA, etc.

Using the layer-by-layer method, Ch and $\gamma$-PGA were assembled into polyelectrolyte multilayers films (PEMs) with thickness of $120 \mathrm{~nm}$. The chemokine stromal-derived factor-1 (SDF-1) was incorporated in these complexes and was continuously released during $120 \mathrm{~h}$. The method of SDF-1 incorporation is of crucial importance for polymers assembly into PEMs and for the release kinetics of this chemokine. The $\mathrm{Ch} / \gamma$-PGA PEMs with SDF-1 were able to recruit hMSCs, increasing the cell migration up to 6 fold to a maximum of $16.2 \pm 4.9$ cells $/ \mathrm{mm}^{2}$. The controlled release of SDF-1 would be of great therapeutic value in the process of hMSC homing to injured tissues. This is the first study suggesting $\mathrm{Ch} / \gamma$-PGA PEMs as SDF-1 reservoirs to recruit hMSCs, describing an efficient method of chemokine incorporation that allows a sustained released up to 5 days and that can be easily scaled-up.
\end{abstract}

Keywords: Mesenchymal stem cells, cell recruitment, layer-by-layer, chitosan, poly $(\gamma$-glutamic acid $)$, protein delivery.

\footnotetext{
*Address for correspondence:

Raquel M. Gonçalves

INEB, R. Campo Alegre,

823 Porto 4150-180, Portugal

E-mail: raquelg@ineb.up.pt
}

\section{Introduction}

Human mesenchymal stem cells (hMSCs) are known as a heterogeneous cell population of multipotent adult stem cells that can be isolated from tissues such as bone marrow or adipose tissue, among others (Uccelli et al., 2008; Sundelacruz and Kaplan, 2009). hMSCs have an enormous differentiation potential, not only into osteogenic, chondrogenic and adipogenic lineages, but also in other tissues as tendon, muscle and marrow stromal connective tissue (Yoo et al., 2009). Their use in tissue engineering has already been reported in bone (Oliveira et al., 2009), cartilage (Hofmann et al., 2006), dermis (Schneider et al., 2010) and heart (Mokashi et al., 2010).

Also, a reduction of the immune response has been associated with these cells: hMSCs were shown to reduce T-cell proliferation and cytotoxicity, natural killer (NK) cells proliferation and IFN- $\gamma$ production and also hinder dendritic cell (DC) activation and maturation (Meirelles et al., 2009; Singer and Caplan, 2011). This action has been explored for graft-versus-host disease, septic shock, auto-immune arthritis, diabetes, multiple sclerosis and lupus (Ichim et al., 2010). Together, these aspects highlight the importance of this cell population and fundament their use in tissue engineering and cell-based therapies (Uccelli et al., 2008).

hMSCs have the ability to migrate into different tissues including bone marrow, muscle, skin, gut, liver, and lung (Fong et al., 2011). The migration process can be regulated by different chemokines and growth factors (e.g., monocyte chemotactic protein-1, stromal-derived factor-1, platelet-derived growth factor (PDGF), vascular endothelial growth factor, etc.) (Ponte et al., 2009). In particular, CXCL-12, or stromal-derived factor-1 $\alpha$ (SDF$1 \alpha)$, is a chemokine constitutively produced in bone marrow, being strongly chemotactic to lymphocytes, but also to monocytes (Bleul et al., 1996), endothelial progenitor cells (Frederick et al., 2010), and responsible for the regulation of the homing process of haematopoietic progenitors (Broxmeyer and Christopherson, 2004). It is also a very important factor during carcinogenesis (Kim et al., 2010). SDF-1 is expressed/secreted by several tissues, with a particular incidence in bone marrow, and is known to bind to CXCR4 receptor (Wynn et al., 2004; Li et al., 2011). The SDF-1/CXCR4 axis is known to regulate the homing process and engraftment of haematopoietic stem cells in bone marrow after transplantation (Peled et al., 1999). More recently, CXCR4 expression on bone marrow stromal cells also has been reported, at low levels in the membrane ( 4\%), but with large expression 


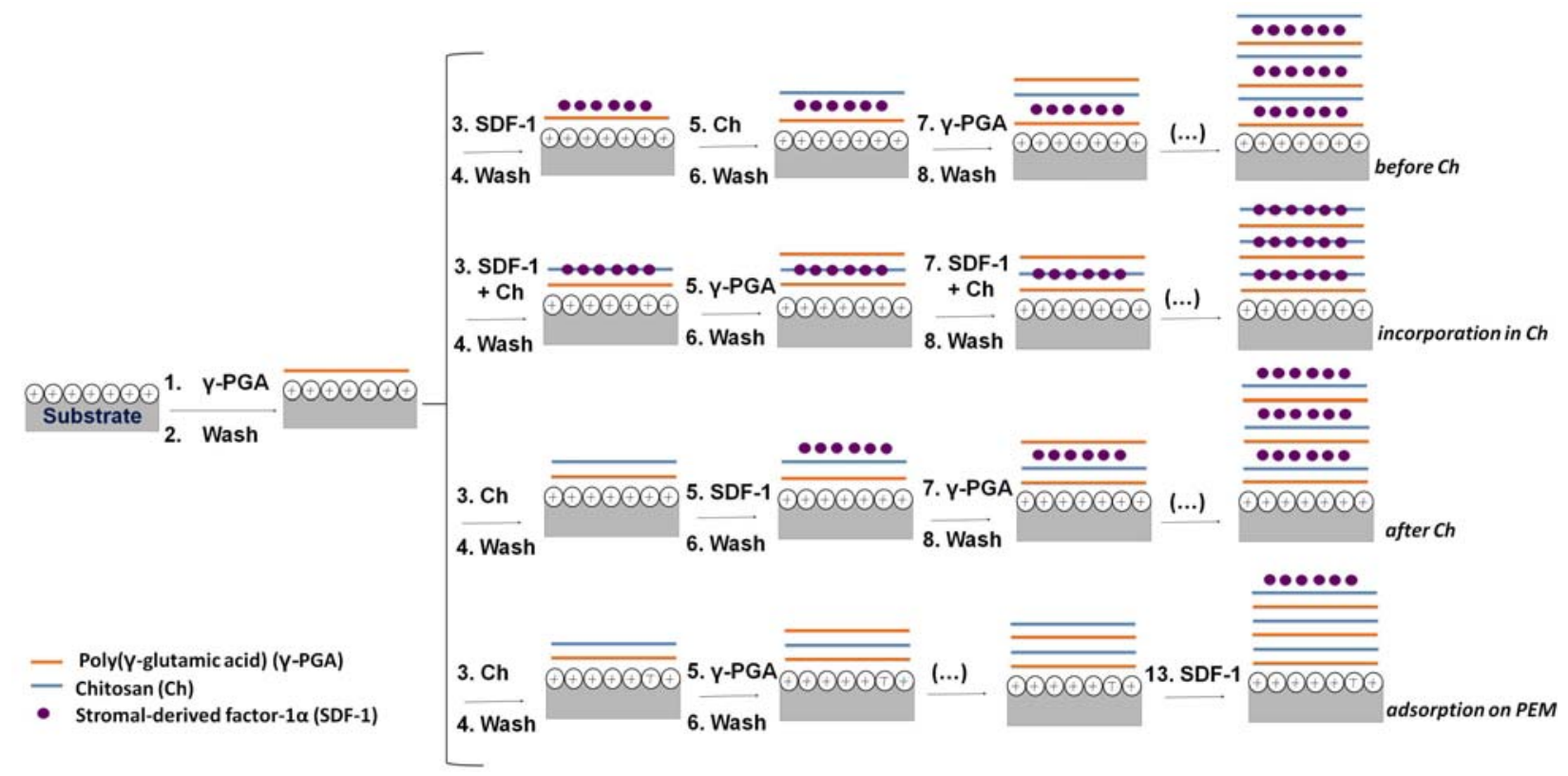

Fig. 1. Schematic overview of the preparation of Chitosan (Ch, blue line) and Poly $(\gamma$-glutamic acid) ( $\gamma$-PGA, orange line) polyelectrolyte multilayer films (PEMs) with SDF-1 (purple circles). Ch substrates prepared by spin coating were immersed in $\gamma$-PGA solution. Four different approaches were used to introduce SDF-1: 1) incorporation before deposition of each $\mathrm{Ch}$ layer (before $\mathrm{Ch}$ ); 2) incorporation within each Ch layer (incorporation in $\mathrm{Ch}$ ); 3) incorporation after deposition of each Ch layer (after $\mathrm{Ch}$ ); and 4) adsorption after assembly of Ch/ $\gamma$-PGA PEMs with 6 layers (adsorption on PEMs).

intracellularly ( $\sim 96 \%$ ) (Wynn et al., 2004). In addition, some studies have shown the migration of hMSCs via SDF-1 signalling (Gao et al., 2009; Ponte et al., 2009), in particular when associated with a pro-inflammatory environment (Wynn et al., 2004; Ponte et al., 2009). hMSCs CXCR4 $4^{+}$sub-population was revealed to be crucial in the process of cell homing to a bone fracture and to the healing process (Granero-Moltó et al., 2009). Therefore, the sustained release of chemoattractors, as SDF-1 aiming to recruit hMSCs to a site of injury would be of great therapeutic value in tissue engineering.

Chitosan ( $\mathrm{Ch}$ ) is a natural polysaccharide composed by units of glucosamine and N-acetylglucosamine that is obtained from deacetylation of chitin, originally found in crustaceans. $\mathrm{Ch}$ is non-toxic, biodegradable and cationic below $\mathrm{pH}$ 6.5, which allows its combination with anionic polymers such as gelatin (Haider et al., 2010), alginate (Wu et al., 2009), poly-lysine (Chi et al., 2008) and poly-(glutamic acid) (Song et al., 2009). These structures can be formed by self-assembly of oppositely charged polyelectrolytes and are known as polyelectrolyte complexes (Boudou et al., 2010).

The layer-by-layer ( $\mathrm{LbL}$ ) deposition technique can be used to obtain polyelectrolyte multilayers (PEMs). The LbL method is easy to perform under mild conditions, allows the incorporation of bioactive molecules or extracellular matrix (ECM) components, and can produce thin films with different mechanical properties. Since these structures allow the control of film properties at the nanoscale, the interest in using them to control diffusion of biomolecules has been growing, particularly with the purpose of designing new drug-eluting coatings and artificial microenvironments (Boudou et al., 2010). These biocompatible structures can be modulated by different factors (e.g., $\mathrm{pH}$, ionic strength, polymer concentrations, etc) and designed to incorporate different molecules (polypeptides, polysaccharides, DNA, proteins, and nanoparticles) (Boudou et al., 2010).

Poly $(\gamma$-glutamic acid) ( $\gamma$-PGA) is a hydrophilic, non-toxic, negatively charged at $\mathrm{pH}$ above 2.2, biodegradable poly-aminoacid microbially synthesised by different strains of Bacillus. $\gamma$-PGA was shown to increase the hydrophilicity and cytocompatibility of $\mathrm{Ch} / \gamma$ PGA biomaterials (Hsieh et al., 2005). Non immunogenic reactions to $\gamma$-PGA have been reported probably linked to the degradation of $\gamma$-PGA into glutamic acid residues, which has a history of safe use in food products (Buescher and Margaritis, 2007). In spite of this, the use of $\gamma$-PGA in tissue engineering applications remains largely unexplored (Buescher and Margaritis, 2007).

Our team recently demonstrated that $\mathrm{Ch}$ can interact electrostatically with $\gamma$-PGA, forming multilayered films (Antunes et al., 2011). These films were extensively characterised and the contribution of the polymers to each layer was highlighted. Also, $\mathrm{Ch} / \gamma$-PGA structures revealed no cytotoxicity. The aim of this investigation was to explore the use of $\mathrm{Ch} / \gamma$-PGA multilayered films as chemokine delivery system for the recruitment of hMSCs.

\section{Materials and Methods}

Preparation of Chitosan/Poly $(\gamma$-glutamic acid) $(\mathrm{Ch} / \gamma$ PGA) polyelectrolyte multilayers (PEMs)

$\mathrm{Ch} / \gamma$-PGA PEMs were prepared as previously described (Antunes et al., 2011). Briefly, Ch (France-Chitine, 
Orange, France; degree of acetylation (DA) of $10.4 \pm 1.6$ $\%$ determined by Fourier Transform Infrared Spectrometry using $\mathrm{KBr}$ pellets (FTIR-KBr), and molecular weight (Mw) of $324 \pm 27 \times 10^{3}$, determined by size-exclusion chromatography) ultrathin films (ca. $20 \mathrm{~nm}$ thickness) were prepared by spincoating on clean gold $\left(0.5 \times 0.5 \mathrm{~cm}^{2}\right)$ for ellipsometry, radiolabelling and ELISA analysis or glass substrates (13 mm diameter) for cell culture assays. After spinning, Ch films were neutralised in $\mathrm{NaOH} 0.1 \mathrm{M}$, for $5 \mathrm{~min}$, rinsed twice in ultrapure water and dried for $24 \mathrm{~h}$ at $37^{\circ} \mathrm{C}$.

$\gamma$-PGA was produced microbially by our group from $B$. subtilis culture with a molecular weight $(\mathrm{Mw})$ of $10-50 \mathrm{kDa}$ and a purity level of $99.5 \%$ (Antunes et al., 2011). Ch/ $\gamma$-PGA PEMs were then formed by layer-bylayer technique. Briefly, Ch ultrathin films were immersed in $\gamma$-PGA solution $(0.2 \mathrm{mg} / \mathrm{mL})$ at $\mathrm{pH} 5$ in buffer Tris- $\mathrm{HCl}$, $\mathrm{NaCl} 0.15 \mathrm{M}$ for $15 \mathrm{~min}$, with gentle stirring. After that, the samples were rinsed with the same buffer, for $2 \mathrm{~min}$. The $\gamma$-PGA/Ch films were immersed in a Ch solution $(0.2 \mathrm{mg} /$ $\mathrm{mL}$ ) at $\mathrm{pH} 5$ in the same buffer as described. This process was repeated until a maximum of $6 \mathrm{Ch} / \gamma$-PGA layers were obtained.

\section{Combination of human Stromal Derived Factor (SDF)-1 alpha (CXCL12) into $\mathrm{Ch} / \boldsymbol{\gamma}$-PGA PEMs}

SDF-1 (Peprotech, Rocky Hill, NJ, USA; 8 kDa, > $98 \%$ purity) was dissolved in buffer Tris- $\mathrm{HCl}, \mathrm{NaCl} 0.15 \mathrm{M}$, at $\mathrm{pH}$ 5, in two concentrations: 100 and $500 \mathrm{ng} / \mathrm{mL}$. Soluble SDF-1 was combined into $\mathrm{Ch} / \gamma$-PGA PEMs using different methods (Fig. 1):

1. SDF-1 solution ( 100 or $500 \mathrm{ng} / \mathrm{mL}$ ) in PBS, incorporated before each Ch layer for $15 \mathrm{~min}$ ("before Ch");

2. SDF-1 solution ( 100 or $500 \mathrm{ng} / \mathrm{mL})$ in Ch solution $(0.2$ $\mathrm{mg} / \mathrm{mL}$ ) incorporated within each $\mathrm{Ch}$ layer for $15 \mathrm{~min}$ ("incorporation in Ch");

3. SDF-1 solution ( 100 or $500 \mathrm{ng} / \mathrm{mL}$ ) in PBS, incorporated after each Ch layer for 15 min ("after Ch");

4. SDF-1 solution (100 or $500 \mathrm{ng} / \mathrm{mL}$ ) in PBS, adsorbed after assembly of $\mathrm{Ch} / \gamma$-PGA PEMs with 6 layers during 15 min (“adsorption in PEM").

\section{Thickness of PEMs}

Thickness of $\mathrm{Ch} / \gamma$-PGA thin films prepared on gold substrates was measured using an Imaging Ellipsometer, model EP3, from Nanofilm Surface Analysis. The ellipsometer was operated in a polariser-compensatorsample-analyser (PCSA) mode (null ellipsometry). The light source was a solid-state laser with a wavelength of $532 \mathrm{~nm}$. Refractive index $(n)$ and extinction coefficient $(k)$ of gold substrates were determined by using a delta and psi spectrum with a variation of angle between $67^{\circ}$ and $72^{\circ}$. To determine the film thickness, the $n$ and $k$ of $\mathrm{Ch}$ and $\gamma$-PGA layers were set to 1 and 0 , respectively. Three areas of three different samples were measured for each condition.

\section{Quantification of SDF-1 in Ch/ $\gamma$-PGA PEMs}

SDF-1 was labelled with ${ }^{125}$ I (Perkin Elmer) using the Iodogen method (Amersham, 1993). Immediately after labelling, ${ }^{125} \mathrm{I}-\mathrm{SDF}-1$ was pre-packed in PD-10 Sephadex
G-25 columns (Amersham Pharmacia. Amersham, UK), previously equilibrated in Phosphate Buffer Solution (PBS). The yield of iodination was estimated by trichloroacetic acid precipitation method (TCA, $10 \%$ $\mathrm{v} / \mathrm{v}$ ) and ranged from 95 to $99 \%$. ${ }^{125} \mathrm{I}-\mathrm{SDF}-1$ solutions at the concentrations of 100 and $500 \mathrm{ng} / \mathrm{mL}$ with the same final activity of $8000 \mathrm{cpm} / \mathrm{ng}$ were combined with $\mathrm{Ch} / \gamma$ PGA PEMs built in gold substrates by the four methods described above. Afterwards, each sample was placed individually into different radioimmune assays (RIA) tubes, washed three times with buffer Tris- $\mathrm{HCl}, \mathrm{NaCl}$ $0.15 \mathrm{M}$ at $\mathrm{pH}$ 5. All samples and SDF-1 standard solutions were counted in a $\gamma$-counter and the amount of protein calculated by:

Protein $\left(\mathrm{ng} / \mathrm{cm}^{2}\right)=$ counts $(\mathrm{cpm}) /\left[A_{\text {solution }}(\mathrm{cpm} / \mathrm{ng}) \times S\left(\mathrm{~cm}^{2}\right)\right](1)$

in which counts is the films-associated radioactivity, $A_{\text {solution }}$ is the specific radioactivity of the protein solution and $S$ is the surface area. Four replicates of each condition were used to determine the number of counts. These experiments were carried out in the presence of $10 \mathrm{nM}$ of $\mathrm{NaI}$ to suppress the adsorption of residual free ${ }^{125} \mathrm{I}$, which ranged from 1 to $5 \%$. Since free ${ }^{125} \mathrm{I}$ may result in increased readings of the adsorbed protein, addition of a small amount of nonradioactive iodide is recommended to suppress free ${ }^{125} \mathrm{I}$ adsorption (Horbett, 1986; Du et al., 2000).

\section{SDF-1 delivery kinetics}

To assess SDF-1 delivery kinetics, SDF-1-containing $\mathrm{Ch} / \gamma$-PGA PEMs were incubated in DMEM supplemented with foetal bovine serum (FBS) (10\%), in a humidified atmosphere at $37^{\circ} \mathrm{C}$, with $5 \%$ of $\mathrm{CO}_{2}$. At each $24 \mathrm{~h}$, up to $120 \mathrm{~h}$, the PEMs containing ${ }^{125} \mathrm{I}-\mathrm{SDF}-1$ were rinsed three times with PBS and the counts of SDF-1-Ch/ $\gamma$-PGA PEMs were measured in the $\gamma$-counter. The cumulative amount of released SDF-1 was calculated by:

$\%$ SDF-1 cumulative release $\left(\mathrm{t}_{1}\right)=\left[\mathrm{SDF}-1\left(\mathrm{t}_{0}\right)-\mathrm{SDF}-1\left(\mathrm{t}_{1}\right)\right] \mathrm{x} 100 / \mathrm{SDF}-1\left(\mathrm{t}_{0}\right)$

in which $S D F-1\left(t_{0}\right)$, is the amount of SDF-1 (ng/ $\mathrm{cm}^{2}$ ) present in $\mathrm{Ch} / \gamma$-PGA PEMs immediately after incorporation/adsorption $(\mathrm{t}=0 \mathrm{~h})$ and $S D F-1\left(t_{1}\right)$, is the amount of SDF-1 $\left(\mathrm{ng} / \mathrm{cm}^{2}\right)$ within $\mathrm{Ch} / \gamma$-PGA PEMs at each $24 \mathrm{~h}$ interval.

The results are presented as the average of four independent samples for each condition. For the Higuchi model kinetics the results were converted as:

$$
\left[\% \text { SDF-1 cumulative release }\left(\mathrm{t}_{1}\right)\right]^{-1}=\log \left(\mathrm{t}_{1}\right)
$$

for each $24 \mathrm{~h}$ up to $120 \mathrm{~h}$, according to the literature (Higuchi, 1963).

To confirm the SDF-1 release, SDF-1 containing PEMs without ${ }^{125}$ I-SDF-1 were incubated in the conditions described above. The culture medium in contact with SDF-1-PEMs was removed at each $24 \mathrm{~h}$, centrifuged at high speed and kept at $-20^{\circ} \mathrm{C}$. SDF-1 released to the medium was then quantified using a commercial ELISA kit for SDF-1 (R\&D Systems; Minneapolis, MN, USA), 


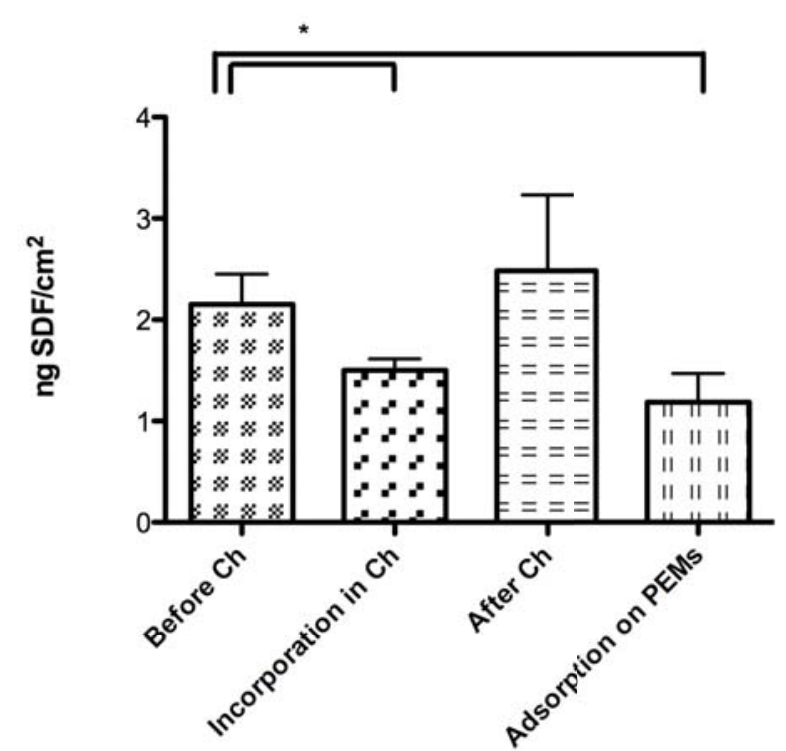

Fig. 2. Combination of SDF-1 in Chitosan (Ch)/Poly $(\gamma-$ glutamic acid) ( $\gamma$-PGA) polyelectrolyte multilayer films (PEMs). SDF-1 (100 ng/mL) was labelled with ${ }^{125} \mathrm{I}$ and incorporated in $\mathrm{Ch} / \gamma$-PGA PEMs by the four approaches presented in Fig. 1: 1) before $\mathrm{Ch}$; 2) incorporation in $\mathrm{Ch}$; 3 ) after $\mathrm{Ch}$; and 4) adsorption on PEMs. The amount of 125I-SDF-1 was quantified in a gamma-radiation counter. Results are presented as Mean $\pm \operatorname{StDev}(n=4)$. Statistical significance was considered for $p<0.05(*)$.

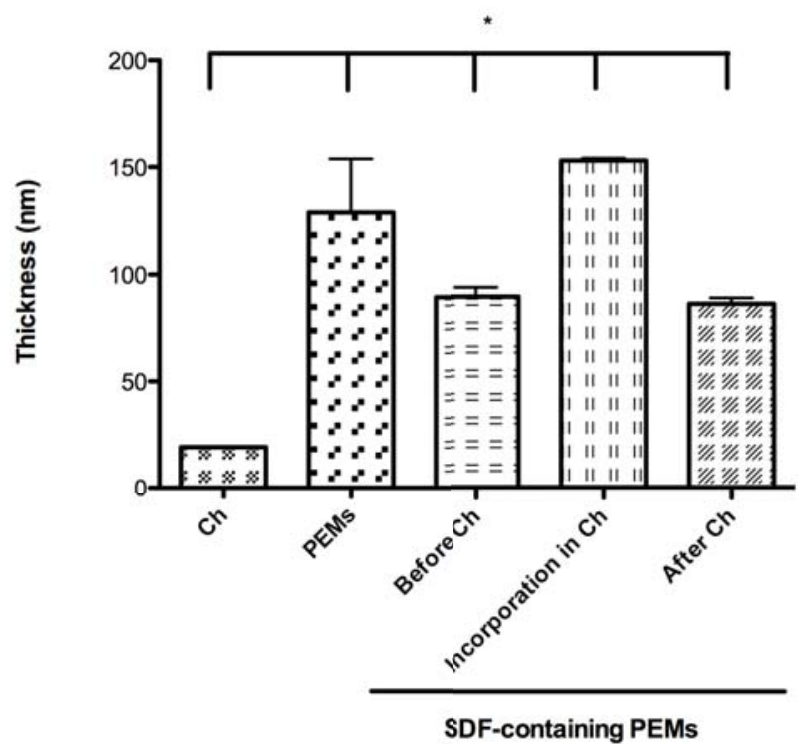

Fig. 3. Thickness of Chitosan $(\mathrm{Ch}) / \operatorname{Poly}(\gamma$-glutamic acid) ( $\gamma$-PGA) polyelectrolyte multilayer films (PEMs) with and without SDF-1. The thickness of $\mathrm{Ch} / \gamma-\mathrm{PGA}$ PEMs (PEMs) and Ch films (Ch) was compared with the thickness of SDF-containing Ch PEMs, either when SDF1 was inserted before (before $\mathrm{Ch}$ ), within (incorporation in $\mathrm{Ch}$ ) and after (after $\mathrm{Ch}$ ) each $\mathrm{Ch}$ layer. Results are presented as Mean $\pm \operatorname{StDev}(3$ areas of $n=3$ ). Statistical significance was considered for $p<0.05(*)$. according to the manufacturer's instructions. The results are presented as the average of three independent samples for each condition.

\section{Human mesenchymal stem cell recruitment by $\mathrm{Ch} /$ $\gamma$-PGA PEMs with SDF-1}

hMSCs were isolated from human bone marrow (BM) collected by Serviço de Ortopedia e Traumatologia from Hospital de São João from discarded bone tissues of patients undergoing total hip arthroplasty, less than 60 years old, and who did not suffer from known inflammatory diseases, following a protocol approved by the ethics committee of the hospital and informed consent by the patients. hMSCs were isolated by adherence method after density gradient centrifugation and characterised as previously described (Almeida et al., 2012). hMSCs were expanded in DMEM-low-glucose medium with Glutamax plus $10 \%$ selected inactivated FBS and $1 \%$ penicillin/ streptomycin (all from Invitrogen/Life Technologies, Carlsbad, CA, USA).

To evaluate MSCs migration, transwells with a polyethylene terephthalate membrane with $8 \mu \mathrm{m}$ pore size and $6.5 \mathrm{~mm}$ diameter (BDFalcon, Franklin Lanes, NJ, USA) were used. The transwells were incubated with $100 \mu \mathrm{L}$ of bovine gelatin solution $0.1 \%$ (Sigma-Aldrich, St. Louis, MO, USA) for $1 \mathrm{~h}$ at $37^{\circ} \mathrm{C}$, as described by other authors (Ponte et al., 2009). After 1 h, the solution was removed and the transwells rinsed with PBS. hMSCs (passage 5 to $7,8 \times 10^{4}$ cells/insert) were then seeded on the top of transwells in $500 \mu \mathrm{L}$ of serum-free medium to potentiate the effect of the chemoattractor. In the bottom wells, Ch/ $\gamma$-PGA PEMs with SDF-1 (0, 100 and $500 \mathrm{ng} /$
$\mathrm{mL})$ were placed in $750 \mu \mathrm{L}$ of serum-free medium. After $6 \mathrm{~h}$ of incubation at $37^{\circ} \mathrm{C}$ in $5 \% \mathrm{CO}_{2}$ environment, cells were fixed with $4 \%$ paraformaldehyde and rinsed with cold PBS. The cell density and time of incubation were selected in accordance with the literature (Ruster et al., 2005; Bhakta et al., 2006). Inserts were carefully washed with cold PBS, and cells remaining on the upper face of the filters were removed with a cotton wool swab, commonly used in this assay (Ponte et al., 2009). The filters were then cut out with a scalpel, stained with DAPI and mounted onto glass slides, with the lower part facing upwards. The number of cells that had migrated was determined by counting 12 fields of observation at 200x magnification using an inverted fluorescence microscopy (Axiovert, Zeiss, Oberkochen, Germany). Data are expressed as numbers of migrated cells per $\mathrm{mm}^{2}$. The results include independent experiments with three different donors (Passage 5 to 7), with one to four samples per condition. One representative control experiment using different concentrations of soluble SDF-1 was also performed ( 0 , $5,10,25,50$ and $100 \mathrm{ng} / \mathrm{mL}$ ) in the conditions previously described, using one donor (2 samples).

\section{Statistics}

The experimental results are presented as the mean plus/ minus the standard deviation (SD). Statistical analysis was performed using GraphPad Prism (La Jolla, CA, USA) vs. 5.0 for Mac OS X. The nonparametric Mann-Whitney test was used to compare the groups of samples. A confidence level of at least $95 \%\left(^{*}, p<0.05, * * p<0.025, * * * p<\right.$ 0.001 ) was used. 

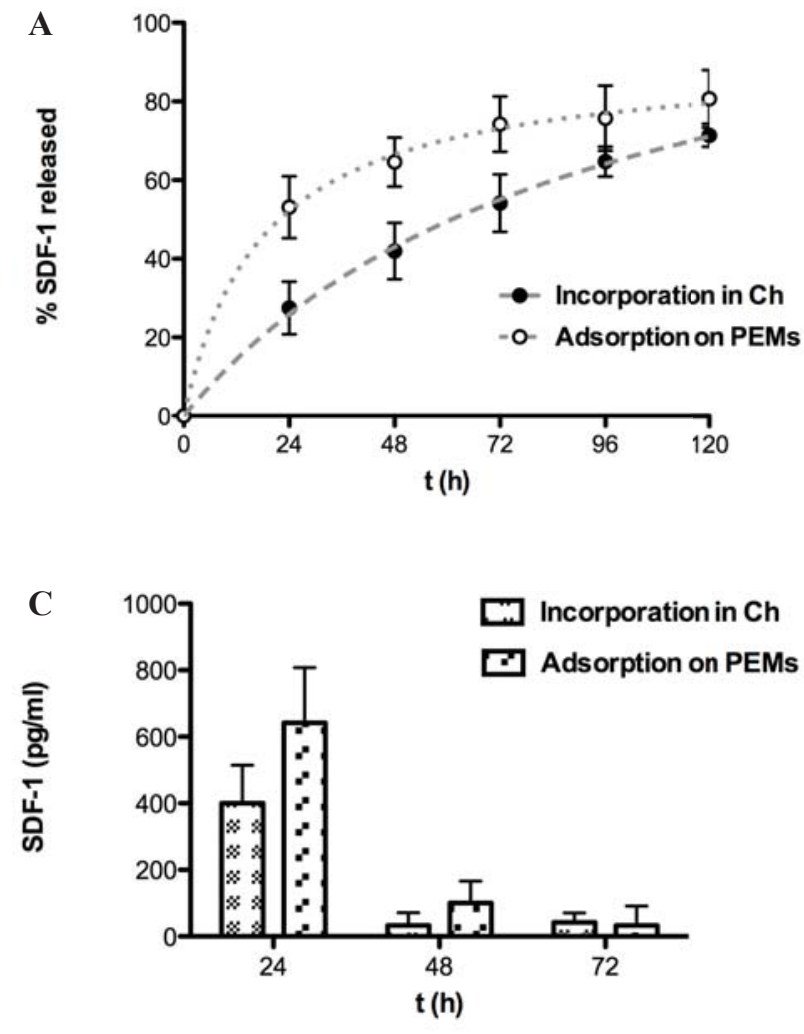

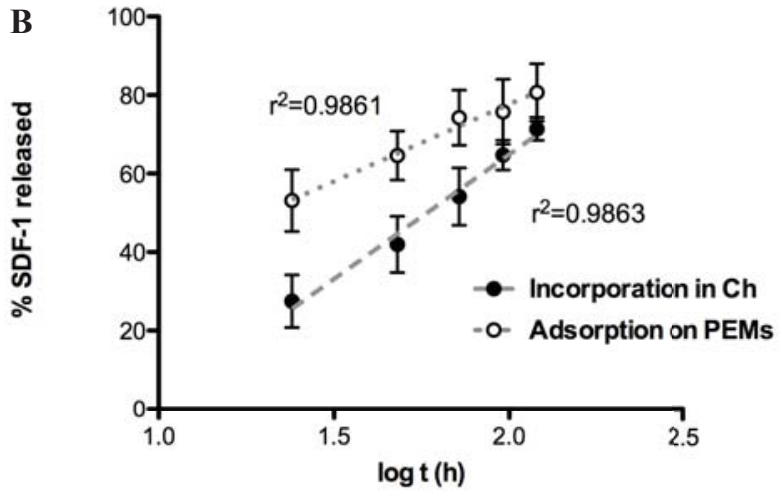

Fig. 4. SDF-1 release kinetics. Chitosan $(\mathrm{Ch}) / \operatorname{Poly}(\gamma-$ glutamic acid) ( $\gamma$-PGA) polyelectrolyte multilayer films (PEMs) with SDF-1 (100 ng/mL), which was either incorporated in $\mathrm{Ch}$ (Incorporation in $\mathrm{Ch}$ ) or adsorbed onto PEMs (Adsorption on PEMs). PEMs were incubated in DMEM supplemented with FBS $(10 \%)$ at $37^{\circ} \mathrm{C}$. The SDF-1 release kinetics was monitored during $120 \mathrm{~h}$ by SDF-1 radiolabelling with ${ }^{125} \mathrm{I}(\mathbf{A})$. The SDF-1 release kinetics follows the Higuchi release model (B). SDF-1 released to the medium was quantified during $72 \mathrm{~h}$ using $\operatorname{ELISA}(\mathbf{C})$. Results are presented as Mean $\pm \operatorname{StDev}(n=$ 4 for $\mathbf{A} ; n=3$ for $\mathbf{B}$ and $\mathbf{C}$ ).

\section{Results}

\section{Combination of SDF-1 into $\mathrm{Ch} / \boldsymbol{\gamma}$-PGA PEMs}

In order to evaluate which is the most suitable strategy to introduce SDF-1 into Ch/ $\gamma$-PGA PEMs, four different methods were used. Since SDF-1, like Ch, is positively charged at $\mathrm{pH} 5.0$, its incorporation in the films was carried out by 3 methods: (1) incorporation before each Ch layer (referred to as "before Ch"); (2) incorporation within each $\mathrm{Ch}$ layer (referred to as "incorporation in Ch"); (3) incorporation after each Ch layer (referred to as "after $C h$ "). Moreover, these methods were compared with SDF-1 adsorption as a final step, i.e. after producing the $\mathrm{Ch} / \gamma$-PGA PEMs with 6 layers (referred to as "adsorption on PEMs") (Fig. 1).

To compare the efficiency of SDF-1 incorporation using the four different strategies, SDF-1 (100 ng/mL in PBS) was previously labelled with ${ }^{125} \mathrm{I}$ and incorporated in $\mathrm{PBS}$ or in a Ch solution. The number of radioactive counts of the PEMs was used to estimate the amount of chemokine present in $\mathrm{Ch} / \gamma$-PGA PEMs (Fig. 2). The results show that the concentration of SDF- 1 in $\mathrm{Ch} / \gamma$-PGA PEMs with 6 layers ranged from $1.2 \pm 0.8 \mathrm{ng} / \mathrm{cm}^{2}$ to $2.5 \pm 1.5 \mathrm{ng} / \mathrm{cm}^{2}$. The amount of SDF-1 incorporated was slightly higher when SDF-1 was incorporated before $\left(2.2 \pm 0.3 \mathrm{ng} / \mathrm{cm}^{2}\right)$ or after $\left(2.5 \pm 1.5 \mathrm{ng} / \mathrm{cm}^{2}\right)$ each Ch layer was deposited. In particular, when SDF-1 was introduced before the $\mathrm{Ch}$ layers, the amount of SDF-1 was significantly higher than when SDF-1 was adsorbed $\left(1.2 \pm 0.8 \mathrm{ng} / \mathrm{cm}^{2}\right)$ or incorporated $\left(1.5 \pm 0.3 \mathrm{ng} / \mathrm{cm}^{2}\right)$ within the Ch layers $(p<$ $0.05)$.

\section{Thickness of $\mathrm{Ch} / \boldsymbol{\gamma}$-PGA PEMs with SDF-1}

The introduction of SDF- 1 in $\mathrm{Ch} / \gamma$-PGA PEMs during the assembly process of $\mathrm{Ch}$ and $\gamma$-PGA might affect $\mathrm{Ch}$ and $\gamma$-PGA spontaneous interaction, and the thickness of the nanofilms. To check this aspect, the thickness was measured by ellipsometry (Fig. 3). The thickness of $\mathrm{Ch}$ substrates $(19.2 \pm 0.1 \mathrm{~nm})$ increased to $129 \pm 25 \mathrm{~nm}$ for $\mathrm{Ch} /$ $\gamma$-PGA PEMs with 6 layers. When SDF-1 was introduced into PEMs within the $\mathrm{Ch}$ solution ("incorporation in $C h$ "), the thickness of PEMs slightly increased, reaching $153 \pm 1 \mathrm{~nm}$. However, the PEM thickness significantly decreased $(p<0.05)$ when SDF-1 was introduced before $(89 \pm 4 \mathrm{~nm})$ or after $(86 \pm 3 \mathrm{~nm})$ the Ch layers. The film thickness reduction observed for the conditions "before $C h$ " and "after Ch" suggests that spontaneous assembly of $\mathrm{Ch}$ and $\gamma$-PGA into PEMs was, in part, hindered. Since SDF-1 is positively charged at $\mathrm{pH} 5.0$, it can bind to $\mathrm{Ch}$ (negatively charged), which may interfere with the electrostatic interactions between $\mathrm{Ch}$ and $\gamma$-PGA and consequently, its assembly process. Nevertheless, when SDF-1 is incorporated within the Ch solution, no reduction in thickness was observed.

\section{SDF-1 release kinetics: comparison between} incorporation and adsorption onto $\mathrm{Ch} / \boldsymbol{\gamma}$-PGA PEMs The release of SDF- 1 from $\mathrm{Ch} / \gamma$-PGA PEMs was determined using radiolabelling and ELISA. $\mathrm{Ch} / \gamma-\mathrm{PGA}$ PEMs with SDF-1 were incubated in DMEM culture medium with FBS $10 \%$, and maintained for $120 \mathrm{~h}$ at 37 ${ }^{\circ} \mathrm{C}$. The amount of SDF- 1 released was determined at 24 $\mathrm{h}$ intervals by assessing the radioactive counts of PEMs 
with ${ }^{125}$ I-SDF-1, and renewing the culture medium at each time point (Fig. 4A). Only the method of incorporation in the Ch layers was investigated, in view of the reduction in thickness observed for the other two methods. Adsorption in the PEM films was used for comparison.

The results show a continuous release of SDF-1 during $120 \mathrm{~h}$ for both methods of SDF-1 combination within PEMs. Immediately following the introduction of SDF-1 in PEMs, the amount of SDF-1 ranged from $1.5 \pm 0.3$ to 1.2 $\pm 0.8 \mathrm{ng} / \mathrm{cm}^{2}$ for the incorporation and adsorption methods, respectively. The SDF-1 release kinetics were slower when SDF-1 was introduced by incorporation compared with the adsorption method: after $24 \mathrm{~h}$, by incorporation, only 27.5 $\pm 6.7 \%$ of chemokine was released to the medium, while for the adsorption method about $53.1 \pm 7.9 \%$ of SDF-1 was already released. These release kinetics slowed down after $24 \mathrm{~h}$. After $120 \mathrm{~h}, 71.4 \pm 2.9 \%\left(0.38 \pm 0.07 \mathrm{ng} / \mathrm{cm}^{2}\right)$ and $80.6 \pm 7.3 \%\left(0.09 \pm 0.03 \mathrm{ng} / \mathrm{cm}^{2}\right)$ of initial SDF-1 were released using the incorporation and adsorption strategies, respectively. Within the time period of these experiments (120 h) SDF-1 release follows the Higuchi release kinetics (Higuchi, 1963), using both strategies, which suggest a release by diffusion to the medium (Fig. 4B).

In parallel, SDF-1 release was determined along the three days by ELISA (Fig. 4C) and the results followed the same trend as the release kinetics determined by radiolabelling. The ELISA allowed the quantification of the amount of SDF-1 effectively released to the medium: after $24 \mathrm{~h}, 400 \pm 115 \mathrm{pg} / \mathrm{mL}$ of SDF-1 incorporated within $\mathrm{Ch}$ had passed into the medium, while in the case of adsorbed SDF-1, $642 \pm 165 \mathrm{pg} / \mathrm{mL}$ of the chemokine were already released. These numbers correspond to an estimated release of 13 and $26 \%$ for the incorporation and adsorption method, respectively. These percentages present the same trend as observed with the SDF-1 radiolabelling, confirming faster release kinetics for adsorbed chemokine. However, there is a slight difference between the values obtained by both techniques. The differences may be due to several reasons, including the use of different standards for both assays, the fact that ELISA measures immunoreactivity of the protein and not the actual amount of protein, or simply due to differences in the accuracy of both methods.

After $72 \mathrm{~h}$, SDF-1 was still being released into the medium, although in much lower percentages $(2 \%)$ than those determined by radiolabelling, confirming the high accuracy of the radioactivity method to determine protein release kinetics compared to ELISA.

\section{Effect of SDF- 1 concentration in $\mathrm{Ch} / \gamma$-PGA PEMs as delivery systems}

To evaluate if the concentrations of SDF-1 could influence the amount of SDF-1 incorporated in the PEMs, and consequently its release kinetics, two different concentrations of soluble SDF-1 (100 and $500 \mathrm{ng} / \mathrm{mL}$ ) were combined with these complexes.

Once more, SDF-1 was labelled with ${ }^{125}$ I and combined with $\mathrm{Ch} / \gamma$-PGA PEMs through incorporation within the Ch solution and adsorption after PEM assembly. The number of radioactivity counts was used to estimate the amount of incorporated/adsorbed chemokine (Fig. 5A). At a concentration of $100 \mathrm{ng} / \mathrm{mL}, 1.5 \pm 0.3 \mathrm{ng} / \mathrm{cm}^{2}$ of SDF1 was incorporated and $1.2 \pm 0.8 \mathrm{ng} / \mathrm{cm}^{2}$ of SDF- 1 were adsorbed. When the concentration of soluble SDF-1 was increased to $500 \mathrm{ng} / \mathrm{mL}$, the amount of this chemokine in PEMs increased, reaching $11.5 \pm 1.7 \mathrm{ng} / \mathrm{cm}^{2}$ (when SDF-1 was incorporated in $\mathrm{Ch}$ ) and $2.0 \pm 0.3 \mathrm{ng} / \mathrm{cm}^{2}$ (when SDF1 was adsorbed on PEMs). This increase corresponds to an about 8-fold increase of incorporated protein, which is significantly higher $(p<0.05)$ than when SDF-1 is adsorbed. Such an increase is related to the process of SDF-1 incorporation, since SDF-1 is present within the Ch 3 layers that constitute the $\mathrm{Ch} / \gamma$-PGA films.

The SDF-1 release kinetics from $\mathrm{Ch} / \gamma$-PGA PEMs was monitored during $120 \mathrm{~h}$ for two concentrations (Fig. 4B,C, for absolute values $(\mathrm{ng} / \mathrm{mL})$ and percentage of chemokine released, respectively). Similar kinetics were obtained independently of SDF-1 concentration. $27.5 \pm 6.7 \%$ and $30.4 \pm 8.6 \%$ of SDF-1 had been released after $24 \mathrm{~h}$, for concentrations of $100 \mathrm{ng} / \mathrm{mL}$ or $500 \mathrm{ng} / \mathrm{mL}$, respectively. After $120 \mathrm{~h}$, these values increased to $71.4 \pm 2.9 \%$ and $70.6 \pm 2.6 \%$, respectively.

\section{Recruitment of hMSCs by SDF-1-containing Ch $/ \gamma$-PGA PEMs}

The ability of SDF-1-Ch/ $\gamma$-PGA PEMs to recruit hMSCs was screened in vitro for 3 donors. hMSCs were seeded on the top of $8 \mu \mathrm{m}$ inserts in the presence of $\mathrm{Ch} / \gamma$-PGA PEMs with or without SDF-1 in the bottom wells. After 6 $\mathrm{h}$, the cells at the upper side of the transwells were carefully removed and the recruited cells (on the lower side) were fixed, the nucleus stained and counted under fluorescence microscopy. The number of cells per $\mathrm{mm}^{2}$ that migrate for each condition is represented in Fig. 6A. The results clearly indicate an increase in hMSC migration in the presence of released SDF-1. Ch/ $\gamma$-PGA PEMs were used as negative control. To discard the possibility of complexes without SDF-1 promoting cell migration, this control was compared with a basal level of cell migration in the presence of tissue culture polystyrene. No significant differences between cell recruitment were observed. When SDF-1 was incorporated in the films, MSCs were able to migrate towards released SDF-1, for both methods of chemokine combination with PEMs. Importantly, the levels of cell migration were donor-dependent. Thus, in the presence of $\mathrm{Ch} / \gamma$-PGA PEMs without chemokine, only $2.0 \pm 0.2$ (donor 2 ) to $6.3 \pm 4.4$ cells $/ \mathrm{mm}^{2}$ (donor 1 ) could be recruited after $6 \mathrm{~h}$. When SDF-1 (100 ng/mL) was introduced within $\mathrm{Ch} / \gamma$-PGA PEMs, the number of recruited cells increased, ranging from $6.5 \pm 0.1$ (donor 2) to $15.6 \pm 2.9$ (donor 1) cells/ $\mathrm{mm}^{2}$ when SDF-1 was incorporated within $\mathrm{Ch}$ and 5.5 \pm 1.6 (donor 2) to $14.8 \pm 0.5$ (donor 3 ) cells $/ \mathrm{mm}^{2}$, when SDF-1 was adsorbed to PEMs. The levels of cell migration increased significantly, from 2.0 to 5.3 -fold $(p<0.05$ from $p<0.001$ ), depending on the method of chemokine incorporation and donor. Nevertheless, when the results of cell migration per donor are analysed, no trend is observed between incorporation and adsorption strategies: in the case of donors 1 and 2, the average cell migration was higher when SDF-1 was incorporated in Ch layers, while for donor 3 the average cell migration was enhanced for SDF-1 adsorbed onto PEMs. 

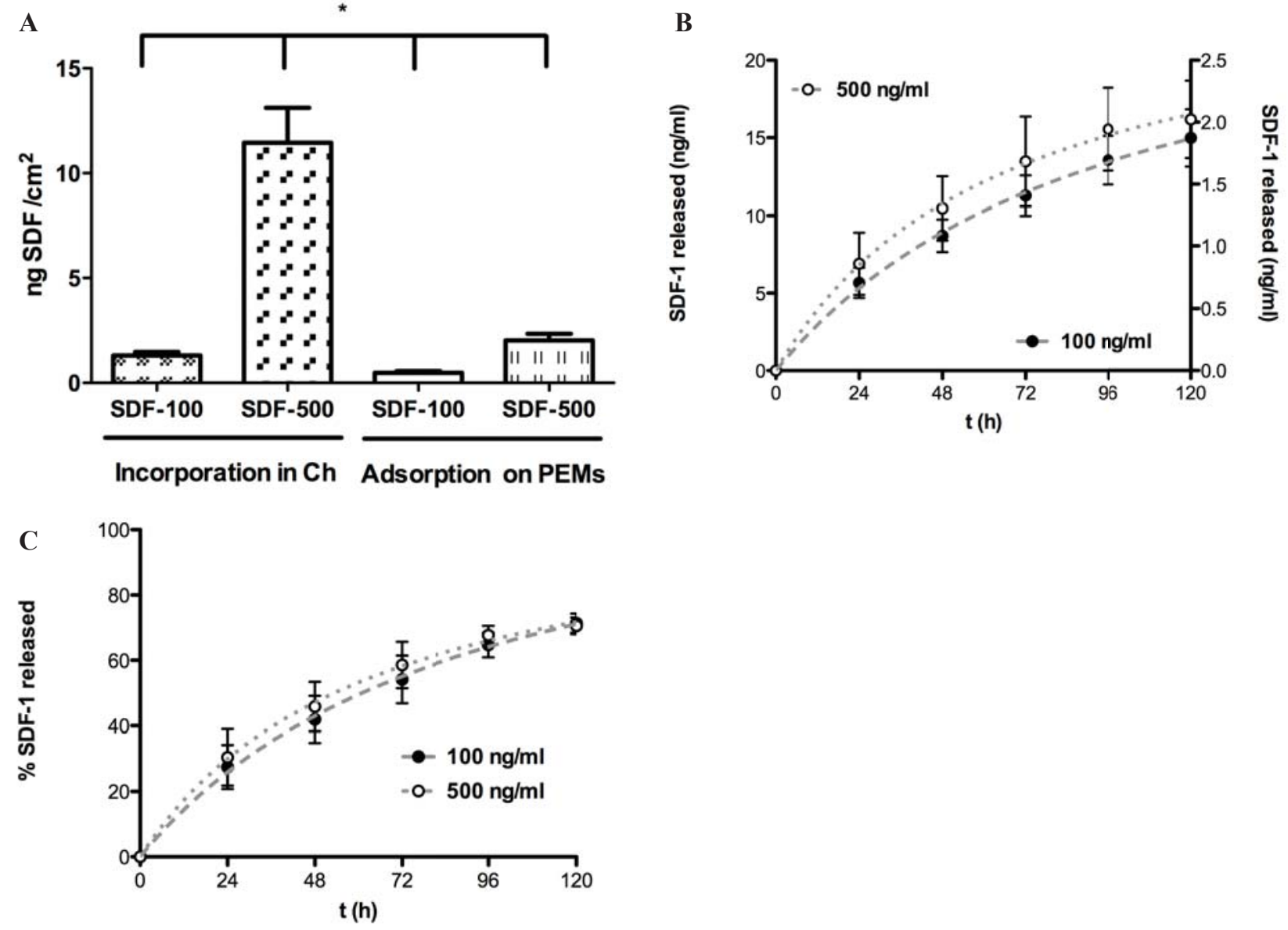

Fig. 5. Effect of SDF-1 concentration in Chitosan $(\mathrm{Ch}) / \mathrm{Poly}(\gamma$-glutamic acid) $(\gamma$-PGA) polyelectrolyte multilayer films (PEMs) on the amount of SDF-1 incorporated in the films. Ch/ $\gamma$-PGA PEMs were obtained using two SDF-1 concentrations in solution (100 ng/mL (SDF-100) and $500 \mathrm{ng} / \mathrm{mL}$ (SDF-500)) and different methods of incorporation: incorporation in the $\mathrm{Ch}$ solution (Incorporation in $\mathrm{Ch}$ ) and adsorption after PEMs assembly (Adsorption on PEMs). The amount of SDF-1, previously labelled with ${ }^{125} \mathrm{I}$, present in PEMs was quantified using a $\gamma$-radiation counter (A). The SDF-1 release kinetics was determined for $120 \mathrm{~h}$. PEMs were incubated in DMEM supplemented with FBS (10 $\%$ ) at $37^{\circ} \mathrm{C}$. A comparison between SDF-1 release using the method of incorporation in Ch with two different SDF-1 concentrations is represented in B and C: total amount of released SDF-1 (ng/mL) (B); relative percentage of released SDF-1 (C). Results are presented as Mean $\pm \operatorname{StDev}(n=4)$. Statistical significance was considered for $p<0.05(*)$.

When SDF-1 concentration increased (from 100 to $500 \mathrm{ng} / \mathrm{mL}$ ), cell migration slightly increased for each donor when SDF-1 was incorporated in Ch layers: (i) donor 1 (from 5.3 to 5.5); (ii) donor 2 (from 3.6 to 4.1); (iii) donor 3 (from 2.0 to 2.2). Similarly, when SDF-1 was adsorbed onto PEMs, the increases were: donor 1 (from 4.6 to 5.4); donor 2 (from 3.0 to 5.4); donor 3 (from 3.0 to 3.1 ). A control experiment was also performed using different concentrations of soluble SDF-1 (Fig. 6B). Cell migration increased when the SDF-1 concentration in solution increased.

\section{Discussion}

This study describes a strategy to recruit hMSCs based on the sustained release of SDF-1. The homing of hMSCs by a strategy as the one described here could be of great therapeutic value. The strategy here described can be used for targeted attraction of specific MSC (sub)-populations with a promising role in tissue regeneration, such as those responding to SDF-1 (Granero-Moltó et al., 2009), to a particular injury site. In this investigation, PEMs were selected as adequate delivery systems due to their versatility and application in drug delivery (Boudou et al., 2010). The integration of SDF- 1 in $\mathrm{Ch} / \gamma$-PGA electrostatic complexes was here described and optimised.

$\mathrm{Ch}$ is a natural polymer widely used in protein/ drug delivery (Barbosa et al., 2011). However, some adjustments can ameliorate this capacity, such as chemical modifications, although some toxicity may be induced. Physical modifications, such as those relying on electrostatic or hydrogen-bonding forces, may result in more adequate delivery carriers. Due to its characteristics, Ch can form PEMs with anionic polymers, which are unique films in the capacity of retaining large amounts of proteins using mild processing conditions, while maintaining adequate protein structure and bioactivity (Macdonald et al., 2011). The LbL technology was selected due to its versatility to incorporate chemokines in various steps of the self-assembly procedure, as indicated in the 


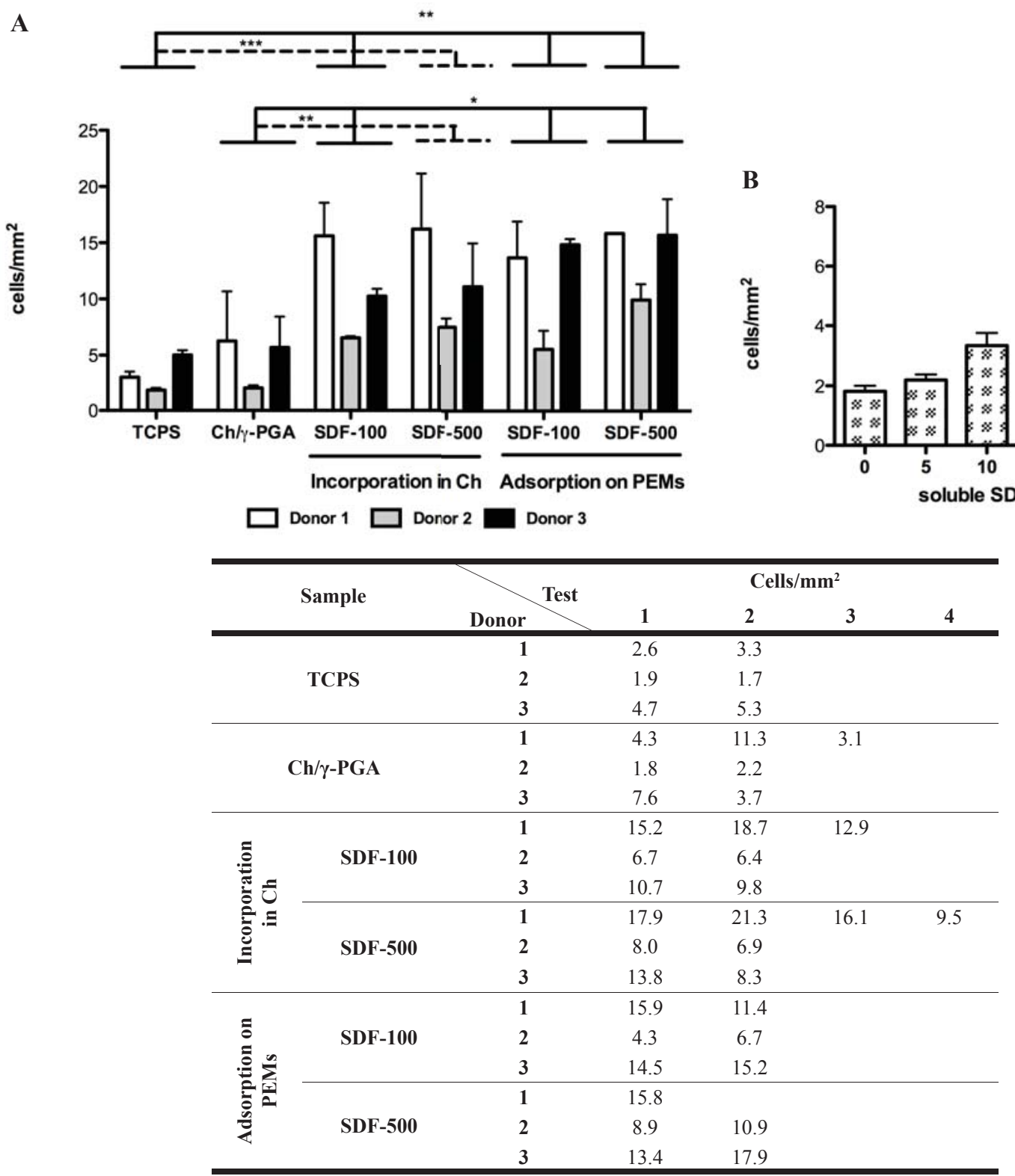

Fig. 6. Migration of human Mesenchymal Stem Cells (hMSCs) in the presence of Chitosan (Ch)/Poly $(\gamma$-glutamic acid) ( $\gamma$-PGA) polyelectrolyte multilayer films (PEMs) with SDF-1. 8x104 hMSCs were seeded on the top of $8 \mu \mathrm{m}$ gelatincoated inserts in RPMI culture medium for $6 \mathrm{~h}$. PEMs with SDF-1 incorporated (Incorporation in Ch) or adsorbed (Adsorption on PEMs) at two different concentrations (100 (SDF-100) and $500 \mathrm{ng} / \mathrm{mL}$ (SDF-500)) were placed in the bottom wells. Tissue-culture polystyrene (TCPS) and Ch/ $\gamma$-PGA PEMs without SDF-1 were used as controls. After incubation, cells were fixed, stained with DAPI and the number of migrated cells counted by fluorescence microscopy (12 microscope fields per sample). The number of migrated cells per $\mathrm{mm}^{2}$ per donor is indicated in the table ( $n$ from 1 to 4 samples per donor; 3 different donors). The average of migrated cells $/ \mathrm{mm}^{2}$ (Mean \pm StDev) per donor is represented in the graphic. Statistical significance was considered for at least $p<0.05(*)$ (A). Example of MSCs migration in the presence of soluble SDF-1 at different concentrations: $0,5,10,25,50$ and $100 \mathrm{ng} / \mathrm{mL}(n=$ 2 samples, 1 donor), illustrating the dependence of the number of migrating cells on chemokine concentration (B).

experimental section (Fig. 1). Examples of biological uses of PEMs in vivo include: increased neuronal activity, enhanced expression of collagen I, inhibition or induction of cell death in tooth development, among others (Boudou et al., 2010).

$\mathrm{SDF}-1$ can be combined with $\mathrm{Ch} / \gamma$-PGA complexes. These complexes built-up in previous studies were extensively characterized, namely concerning its cytocompatibility (Antunes et al., 2011). At the $\mathrm{pH}$ of $\mathrm{Ch}$ and $\gamma$-PGA interaction, SDF-1 is positively charged ( $\mathrm{pI}=$ 10.9, (Bleul et al., 1996)) which can promote binding to the negatively charged $\gamma$-PGA. The combination of SDF1 with $\mathrm{Ch} / \gamma$-PGA complexes was attempted by different approaches. However, not all the strategies tested were effective: when SDF-1 is introduced before a Ch layer is deposited, we hypothesise the chemokine may bind directly to $\gamma$-PGA, impeding the electrostatic binding of Ch to $\gamma$-PGA in the subsequent layers; also, when SDF-1 is 
introduced after Ch deposition, different things can happen, including $\mathrm{Ch}$ adsorption, inter-penetration of the molecules in Ch layers, or conformation changes (Picart et al., 2002; Richert et al., 2003), which may obstruct the binding of the carboxyl groups of $\gamma$-PGA to the amine groups of $\mathrm{Ch}$, decreasing the complexes thickness.

There is evidence that PEMs can constitute reservoirs of significant amounts of proteins (e.g., for BMP-2 and VEGF) by their physical adsorption (Hsieh et al., 2006; Huang et al., 2007; Crouzier et al., 2009). In this work we have also used SDF-1 adsorption on PEMs as a comparative strategy to SDF-1 incorporation during PEMs assembly. With both strategies SDF-1 is continuously released up to 5 days, in cell culture conditions (serum-containing medium, $\mathrm{pH} 7.4,37^{\circ} \mathrm{C}$ ) (Fig. 4). However, the release kinetics present some differences. With incorporation of SDF-1 in the Ch layers the rate of release (given by the slope of the straight lines in Fig. 4B) is faster than when SDF-1 is adsorbed, although both strategies tend towards the same percentage of chemokine released after $120 \mathrm{~h}(\sim 80-90 \%)$. In a previous study, using self-assembled monolayers, we observed that after $120 \mathrm{~h}$ about $50 \%$ of epidermal growth factor was still adsorbed to these surfaces (Gonçalves et al., 2010). This release profile is in agreement with data obtained with alginate substrates for SDF-1 release, in which SDF-1 total release was achieved after 10 days, and $70 \%$ after $120 \mathrm{~h}$ (Rabbany et al., 2010; Kuraitis et al., 2011).

The method of adsorption provides a more rapid initial release (burst at $24 \mathrm{~h}$ ), which is plausible since the chemokine is present at the surface only. Moreover, during the release period, both strategies fit the well-known Higuchi model of release, suggesting the diffusion process as the primary mechanism of SDF-1 release (Higuchi, 1963). In theory, the chemokine should be released due to the disruption of electrostatic interactions at physiologic $\mathrm{pH}$. The diffusion of molecules from PEMs depends on parameters such as film internal structure and nanoporosity, and may be modulated by ionic strength, $\mathrm{pH}$, temperature (De Geest et al., 2007). A steady-state of chemokine release is attained after several days. Other studies using PEMs as protein reservoirs indicate that an initial burst occurs, followed by a steady state of protein release (Crouzier et al., 2009).

SDF-1 was also detected by ELISA in the supernatants. The results obtained follow the trend determined using radiolabelling, although ELISA seems much less sensitive. After $24 \mathrm{~h} \mathrm{SDF}-1$ was also detected in higher amounts in the supernatant when adsorbed into PEMs (higher release rate).

In vivo, SDF-1 is produced in large quantities by bone marrow stromal cells, remaining strongly bound to glycosaminoglycans at sites of production (Bleul et al., 1996). In vitro, it was already demonstrated a maximum of chemoattractant activity with $100 \mathrm{ng} / \mathrm{mL}$ of soluble SDF1, for the recruitment of haematopoietic stem cells (Kim and Brozmeyer, 1998). In addition, Kim and Broxmeyer have also shown SDF-1-dependent migration during 5 $\mathrm{h}$, after which it stopped, being inclusively inhibited for concentrations of $1000 \mathrm{ng} / \mathrm{mL}$ (Kim and Broxmeyer, 1998).
The effect of the initial concentration of SDF-1 on the amount of incorporated/adsorbed chemokine in the PEMs was also evaluated. When a lower SDF-1 concentration (100 ng/mL) was used, both incorporation/adsorption strategies result in similar protein concentrations (1.2 \pm 0.8 to $1.5 \pm 0.3 \mathrm{ng}$ of chemokine per $\mathrm{cm}^{2}$ of PEMs, respectively). For higher SDF-1 concentrations, the amount of retained protein increases to $11.5 \pm 1.7$ and $2.0 \pm 0.3 \mathrm{ng} /$ $\mathrm{cm}^{2}$, for protein incorporation and adsorption, respectively (Fig. 5). The difference in both strategies is probably related to the fact that SDF-1 is present in $3 \mathrm{Ch}$ layers when the incorporation method is adopted, whereas adsorption leads to retention of the protein in the outermost layers. Thus, the incorporation strategy can retain significantly higher amounts of protein, which suggests an important advantage of this process when considering $\mathrm{LbL}$ as protein reservoirs. In these $\mathrm{Ch} / \gamma$-PGA PEMs with 6 layers, from 5 to $10 \%$ of the protein in solution was retained. In spite of being low, we did not attempt to increase it since the purpose of this work was not to optimise the percentage of chemokine retention, but to evaluate cell recruitment.

Although the amount of chemokine in PEMs was different for the two methods, the release kinetics was maintained (Fig. 5B,C). The values of incorporated SDF-1 in PEMs obtained by LbL are in the range of $1-5 \mathrm{ng} / \mathrm{cm}^{2}$ of substrate surface area, with 6 layers of PEMs that have total thicknesses of 100 to $150 \mathrm{~nm}$. However, other authors have produced LbLs using computerised equipment, depositing 100 layers with a total thickness of $2000 \mathrm{~nm}$ (Macdonald et al., 2011). These authors were able to incorporate $700 \mathrm{ng}$ of BMP-2 per mg of scaffold, which suggests the ability of this strategy to incorporate considerable amounts of SDF-1 (Macdonald et al., 2011).

hMSCs can migrate through an SDF-1 gradient due to the expression of CXCR4 receptor but also CXCR7 receptor (Gao et al., 2009; Thieme et al., 2009). Although scarce, (1-4\% of CXCR4 membrane expression, while 83-93\% of CXCR4 cytoplasm expression, (Wynn et al., 2004) and 2-4 \% of CXCR7 membrane expression (Liu et al., 2010)), the sub-population of hMSCs expressing CXCR4 was shown to be crucial for cells homing and healing process in a tibia injury (Granero-Moltó et al., 2009).

The effect of SDF-1-containing PEMs on hMSC recruitment was evaluated by in vitro chemoattraction tests. The results obtained demonstrated that this chemokine retains its biological activity after combination within $\mathrm{Ch} / \gamma$-PGA complexes, increasing MSCs migration from 2 to 6 times when compared with control conditions (Fig. $6)$. This highlights the ability of $\mathrm{Ch} / \gamma$-PGA PEMs to act as SDF-1 delivery system, independently of the chemokine incorporation/adsorption method. Although no differences were observed between both methods in the classic Boyden chamber assay, it remains to be explored how this could affect cell migration in long-term and in vivo assays.

Importantly, a donor-dependent effect on MSC recruitment was observed. This variability may be related with the profile of receptor expression of each donor. Other authors have also described the variability among different donors in MSCs cytokine/chemokine secretion profile, as 
well as in MSCs migration towards chemokines gradients (including SDF-1) (Zhukareva et al., 2010; Ciuculescu et al., 2011).

The interest in SDF-1 use in tissue regeneration is considerable. Recent findings demonstrate that SDF-1 overexpression, together with monocyte chemotactic protein-3 (MCP-3), enhances cell repopulation with osteoblastic progenitors recruited from circulation (Shinohara et al., 2011). Another approach points SDF-1 expression as the key factor to promote cardiac stem cell migration to an infarcted heart, which can lead to reduction in infarct size (Tang et al., 2011). These findings support the potential of the local delivery of this molecule in injured tissues.

Some SDF-1 delivery systems have been reported up to now, namely poly(lactic-co-glycolic acid) (PLGA) 3D scaffolds (Thevenot et al., 2010), silk-collagen gels (Shen et al., 2010) or alginate patches (Rabbany et al., 2010). However, the modulation of SDF-1 release kinetics and the potential of released SDF-1 to recruit hMSCs have not been reported to the best of our knowledge.

In this study, we addressed the use of $\mathrm{Ch} / \gamma$-PGA PEMs as SDF-1 delivery systems, demonstrating how to optimise the incorporation of this chemokine, without significantly interfering with the polymers assembly. By incorporating the chemokine in LbL constructs, we achieved a slower SDF-1 release rate (30\% released after $24 \mathrm{~h}$ ) than other strategies of adsorption already described (Rabbany et al., 2010; Shen et al., 2010), which could be crucial when a sustained delivery through time is required. Furthermore, we demonstrated the ability of released SDF-1 to recruit hMSCs in vitro. Therefore, the sustained and controlled release of SDF-1 could be of major importance in diverse regenerative approaches.

\section{Conclusions}

$\mathrm{Ch}$ and $\gamma$-PGA can interact by electrostatic interaction into PEMs, providing a flexible platform for protein incorporation with minimal alterations in protein activity and affording release of bioactive substances, such as chemokines.

In this study, $\mathrm{Ch} / \gamma$-PGA PEMs were used as delivery systems for SDF-1, a well-known chemokine able to recruit, among others, hMSCs. hMSC recruitment is clinically relevant for minimally invasive strategies to promote tissue regeneration, to control inflammation, and also to support angiogenesis.

The rate of SDF-1 release kinetics is dependent on the method of chemokine introduction in the PEMs. Moreover, the process of chemokine incorporation was found to be crucial for $\mathrm{Ch}$ and $\gamma$-PGA assembly into PEMs. When SDF-1 is incorporated within Ch layers a sustained rate of release is obtained up to 5 days.

Independently of the method of SDF-1 introduction into PEMs, the released chemokine maintain its potential to recruit hMSCs in vitro. Strategies as the one described would be of great therapeutic value in regenerative medicine approaches.

This is the first study suggesting $\mathrm{Ch} / \gamma$-PGA PEMs as SDF-1 reservoirs to recruit hMSCs, describing an efficient method of chemokine incorporation that allows a sustained release of this chemokine.

\section{Acknowledgements}

This work was financed by FEDER funds through the Programa Operacional Factores de Competitividade COMPETE, by Portuguese funds through FCT - Fundação para a Ciência e a Tecnologia, in the framework of the project PEst-C/SAU/LA0002/2011 and by the European project "DISC Regeneration", grant agreement No NMP3LA-2008-213904 (FP7). We are also grateful to FCT for Joana C. Antunes Ph.D. grant SFRH/BD/ 787 48554/2008. We would like also to acknowledge to Dr. Catarina Almeida (INEB) for kindly gifted hMSC, and Dr. Cristina Martins (INEB) for the help with protein radiolabelling.

\section{References}

Almeida CR, Vasconcelos DP, Gonçalves R, Barbosa MA (2012) Enhanced mesenchymal stromal cell recruitment via Natural Killer cells by incorporation of inflammatory signals in biomaterials. J R Soc Interface 9: 261-271.

Amersham (1993) Iodine-125. A guide to radioiodination techniques. (I.-A.g.t.r. techniques, ed), Amersham Life Science, Little Chalfort, UK.

Antunes J, Pereira CL, Molinos M, Ferreira da Silva F, Dessi M, Gloria A, Ambrosio L, Gonçalves RM, Barbosa MA (2011) Layer-by-layer self-assembly of Chitosan and Poly $(\gamma$-glutamic acid) into polyelectrolyte complexes. Biomacromolecules 12: 4183-4195.

Barbosa M, Pêgo AP, Amaral IF (2011) Chitosan. In: Comprehensive Biomaterials, $1^{\text {st }}$ ed (Hutmacher DW, Grainger DW, Healy K, Kirkpatrick CJ, Ducheyne P, eds), Elsevier Amsterdam.

Bhakta S, Hong P, Koc O (2006) The surface adhesion molecule CXCR4 stimulates mesenchymal stem cell migration to stromal cell-derived factor-1 in vitro but does not decrease apoptosis under serum deprivation. Cardiovasc Revasc Med 7: 19-24.

Bleul C, Fuhlbrigge RC, Casasnovas JM, Aiuti A, Springer TA (1996) A highly efficacious lymphocyte chemoattractant, stromal cell-derived factor 1 (SDF-1). J Exp Med 184: 1101-1109.

Boudou T, Crouzier T, Ren K, Blin G, Picart C (2010) Multiple functionalities of polyelectrolyte multilayer films: New biomedical applications. Adv Mat 22: 441-467.

Broxmeyer HE, Christopherson 2nd KW (2004) Stromal cell derived factor-1/CXCL12, CXCR4 and CD26 in the mobilization and homing of hematopoietic stem and progenitor cells. Curr Med Chem - Anti-Inflammatory \& Anti-Allergy Agents 3: 303-311.

Buescher J, Margaritis A (2007) Microbial biosynthesis of polyglutamic acid biopolymer and applications in the biopharmaceutical, biomedical and food industries. Crit Rev Biotechnol 27: 1-19. 
Chi P, Wang J, Liu C (2008) Synthesis and characterization of polycationic chitosan-graft-poly (L-lysine). Mat Lett 62: 147-150.

Ciuculescu F, Giesen M, Deak E, Lang V, Seifried E, Henschler R (2011) Variability in chemokine-induced adhesion of human mesenchymal stromal cells. Cytother 13: $1172-1179$.

Crouzier T, Ren K, Nicolas C, Roy C, Picart C (2009) Layer-by-layer films as a biomimetic reservoir for rhBMP-2 delivery: Controlled differentiation of myoblasts to osteoblasts. Small 5: 598-608.

De Geest B, Sanders NN, Sukhorukov GB, Demeester J, De Smedt SC (2007) Release mechanisms for polyelectrolyte capsules. Chem Soc Rev 36: 636-649.

Du YJ, Cornelius RM, Brash JL (2000) Measurement of protein adsorption to gold surface by radioiodination methods: suppression of free iodide sorption. Colloid Surf B 17: 59-67.

Fong ELS, Chan CK, Goodman SB (2011) Stem cell homing in musculoskeletal injury. Biomaterials 32: 395409.

Frederick J, Fitzpatrick JR 3rd, McCormick RC, Harris DA, Kim AY, Muenzer JR, Marotta N, Smith MJ, Cohen JE, Hiesinger W, Atluri P, Woo YJ (2010) Stromal cell-derived factor-1alpha activation of tissue-engineered endothelial progenitor cell matrix enhances ventricular function after myocardial infarction by inducing neovasculogenesis. Circulation 122: S107-117.

Gao H, Priebe W, Glod J, Banerjee D (2009) Activation of signal transducers and activators of transcription 3 and focal adhesion kinase by stromal cell-derived factor 1 is required for migration of human mesenchymal stem cells in response to tumor cell-conditioned medium. Stem Cells 27: 857-865

Gonçalves R, Martins MCL, Oliveira MJ, AlmeidaPorada G, Barbosa MA (2010) Bioactivity of immobilized EGF on self-assembled monolayers: Optimization of the immobilization process. J Biomed Mater Res Part A 94A: 576-585.

Granero-Moltó F, Weis JA, Miga MI, Landis B, Myers TJ, O'Rear L, Longobardi L, Jansen D, Mortlock DP, Spagnoli A (2009) Regenerative effects of transplanted mesenchymal stem cells in fracture healing. Stem Cells 27: 1887-1898.

Haider S, Al-Masry WA, Bukhari N, Javid M (2010) Preparation of the chitosan containing nanofibers by electrospinning chitosan-gelatin complexes. Polymer Eng Sci 50: 1887-1893.

Higuchi T (1963) Mechanism of sustained-action medication. Theoretical analysis of rate of release of solid drugs dispersed in solid matrices. J Pharm Sci 52: 11451149 .

Hofmann S, Knecht S, Langer R, Kaplan DL, VunjakNovakovic G, Merkle HP, Meinel L (2006) Cartilage-like tissue engineering using silk scaffolds and mesenchymal stem cells. Tissue Eng 12: 2729-2738.

Horbett T (1986) Techniques for protein adsorption studies. In: Techniques of Biocompatibility Tests (Williams DF, ed), CRC Press, Boca Raton, FL, pp 183-214.

Hsieh C, Hsieh, HJ, Liu, HC, Wang, DM, Hou, LT (2006) Fabrication and release behavior of a novel freeze- gelled chitosan $/ \gamma$-PGA scaffold as a carrier for rhBMP-2. Dental Mater 22: 622-629.

Hsieh C, Tsai SP, Wang DM, Chang YN, Hsieh HJ (2005) Preparation of PGA/chitosan composite tissue engineering matrices. Biomaterials 26: 5617-5623.

Huang M, Vitharana SN, Peek LJ, Coop T, Berkland C (2007) Polyelectrolyte complexes stabilize and controllably release Vascular Endothelial Growth Factor. Biomacromolecules 8: 1607-1614.

Ichim T, Alexandrescu DU, Solano F, Lara F, Campion Rde N, Paris E, Woods EJ, Murphy MP, Dasanu CA, Patel AN, Marleau AM, Leal A, Riordan NH (2010) Mesenchymal stem cells as anti-inflammatories: Implications for treatment of Duchenne muscular dystrophy. Cell Immunol 260: 75-82.

Kim C, Broxmeyer HE (1998) In vitro behavior of hematopoietic progenitor cells under the influence of chemoattractants: Stromal cell-derived factor-1, Steel factor, and the bone marrow environment. Blood 91: 100110.

Kim M, Koh YJ, Kim KE, Koh BI, Nam DH, Alitalo K, Kim I, Koh GY (2010) CXCR4 signaling regulates metastasis of chemoresistant melanoma cells by a lymphatic metastatic niche. Cancer Res 70: 10411-10421.

Kuraitis D ZP, Zhang Y, Padavan DT, McEwan K, Sofrenovic T, McKee D, Zhang J, Griffith M, Cao X, Musarò A, Ruel M, Suuronen EJ (2011) Controlled release of stromal cell-derived factor-1 from a collagen matrix for enhanced progenitor cell response and blood vessel growth in ischemia. Eur Cell Mater 5: 109-123.

Li T, Li H, Wang Y, Harvard C, Tan JL, Au A, Xu Z, Jablons DM, You L (2011) The expression of CXCR4, CXCL12 and CXCR7 in malignant pleural mesothelioma. J Pathol 223: 519-530.

Liu H, Xue W, Ge G, Luo X, Li Y, Xiang H, Ding X, Tian P, Tian X (2010) Hypoxic preconditioning advances CXCR4 and CXCR7 expression by activating HIF-1a in MSCs. Biochem Biophys Res Commun 401: 509-515.

Macdonald M, Samuel RE, Shah NJ, Padera RF, Beben YM, Hammond PT (2011) Tissue integration of growth factor-eluting layer-by-layer polyelectrolyte multilayer coated implants. Biomaterials 32: 1446-1453.

Meirelles Lda, Fontes AM, Covas DT, Caplan AI (2009) Mechanisms involved in the therapeutic properties of mesenchymal stem cells. Cytokine Growth Factor Rev 20: 419-427.

Mokashi SA, Guan J, Wang D, Tchantchaleishvili V, Brigham M, Lipsitz S, Lee LS, Schmitto JD, Bolman 3rd RM, Khademhosseini A, Liao R, Chen FY (2010) Preventing cardiac remodeling: The combination of cell-based therapy and cardiac support therapy preserves left ventricular function in rodent model of myocardial ischemia. J Thoracic Cardiovasc Surg 140: 1374-1380.

Oliveira SM, Mijares DQ, Turner G, Amaral IF, Barbosa MA, Teixeira CC (2009) Engineering endochondral bone: In vivo studies. Tissue Eng A 15: 635643.

Peled A, Petit I, Kollet O, Magid M, Ponomaryov T, Byk T, Nagler A, Ben-Hur H, Many A, Shultz L, Lider O, Alon R, Zipori D, Lapidot T (1999) Dependence of 
human stem cell engraftment and repopulation of NOD/ SCID mice on CXCR4. Science 283: 845-848.

Picart C, Mutterer J, Richer L, Luo Y, Prestwich GD, Schaaf P, Voegel JC, Lavalle P (2002) Molecular basis for the explanation of the exponential growth of polyelectrolyte multilayers. Proc Natl Acad Sci USA 99: 12531-12535.

Ponte A, Marais E, Gallay N, Langonne A, Delorme B, Herault E, Charboard P, Domenech J (2009) The in vitro migration capacity of human bone marrow mesenchymal stem cells: Comparison of chemokine and growth factor chemotactic activities. Stem Cells 25: 1737 1745.

Rabbany S, Pastore J, Yamamoto M, Miller T, Rafii S, Aras R, Penn M (2010) Continuous delivery of stromal cell-derived factor-1 from alginate scaffolds accelerates wound healing. Cell Transplant 19: 399-408.

Richert L, Lavalle P, Payan E, Shu XZ, Prestwich GD, Stoltz JF, Schaaf P, Voegel JC, Picart C (2003) Layer by layer buildup of polysaccharide films: Physical chemistry and cellular adhesion aspects. Langmuir 20: 448-458.

Ruster B, Grace, B, Seitza, O, Seifried, E, Henschler R (2005) Induction and detection of human mesenchymal stem cell migration in the 48-well reusable Transwell assay. Stem Cells Dev 14: 231-235.

Schneider RK, Anraths J, Kramann R, Bornemann J, Bovi M, Knöchel R, Neuss S (2010) The role of biomaterials in the direction of mesenchymal stem cell properties and extracellular matrix remodelling in dermal tissue engineering. Biomaterials 31: 7948-7959.

Shen W, Chen, X, Chen J, Yin, Z, Heng, BC, Chen W, Ouyang HW (2010) The effect of incorporation of exogenous stromal cell-derived factor- 1 alpha within a knitted silk-collagen sponge in tendon regeneration. Biomaterials 31: 7239-7249.

Shinohara K, Greenfield, S, Pan H, Vasanji A, Kumagai K, Midura RJ, Kiedrowski M, Penn MS, Muschler GF (2011) Stromal cell-derived factor-1 and monocyte chemotactic protein-3 improve recruitment of osteogenic cells into sites of musculoskeletal repair. J Orthop Res 29: 1064-1069.

Singer N, Caplan AI (2011) Mesenchymal stem cells: Mechanisms of inflammation. Annu Rev Pathol Mech Dis 6: 457-478.

Song Z, Yin J, Luo K, Zheng Y, Yang Y, Li Q, Yan S, Chen X (2009) Layer-by-layer buildup of poly(Lglutamic acid)/chitosan film for biologically active coating. Macromol Biosci 9: 268-278.

Sundelacruz S, Kaplan DL (2009) Stem celland scaffold-based tissue engineering approaches to osteochondral regenerative medicine. Sem Cell Dev Biol 20: 646-655.

Tang J, Wang JN, Zhang L, Zheng F, Yang JY, Kong X, Guo LY, Chen L, Huang YZ, Wan Y, Chen SY (2011) VEGF/SDF-1 promotes cardiac stem cell mobilization and myocardial repair in the infarcted heart. Cardiovasc Res 91: 402-411.

Thevenot P, Nair AM, Shen J, Lotfi P, Ko CY, Tang L (2010) The effect of incorporation of SDF-1a into PLGA scaffolds on stem cell recruitment and the inflammatory response. Biomaterials 31: 3997-4008.

Thieme S, Ryser M, Gentsch M, Navratiel K, Brenner S, Stiehler M, Rolfing J, Gelinsky M, RosenWolff A (2009) Stromal cell-derived factor-1a-directed chemoattraction of transiently CXCR4-overexpressing bone marrow stromal cells into functionalized three dimensional biomimetic scaffolds. Tissue Eng C 15: 687 696.

Uccelli A, Moretta L, Pistoia V (2008) Mesenchymal stem cells in health and disease. Nat Rev Immunol 8: 726-736.

Wu MY, Chen N, Liu LK, Yuan H, Li QL, Chen SH (2009) Chitosan/alginate multilayer scaffold encapsulating bone marrow stromal cells in situ on titanium. J Bioact Compat Polym 24: 301-315.

Wynn R, Hart CA, Corradi-Perini C, O’Neill L, Evans CA, Wraith JE, Fairbairn LJ, Bellantuono I (2004) A small proportion of mesenchymal stem cells strongly expresses functionally active CXCR4 receptor capable of promoting migration to bone marrow. Blood 104: 2643 2645.

Yoo K, Jang, IK, Lee MW, Kim HE, Yang MS, Eomb Y, Lee JE, Kim YJ, Yan, SK, Jung HL, Sung KW, Kim CW, Koo HH (2009) Comparison of immunomodulatory properties of mesenchymal stem cells derived from adult human tissues. Cellr Immunol 259: 150-156.

Zhukareva V, Obrocka M, Houle JD, Fischer I, Neuhuber B (2010) Secretion profile of human bone marrow stromal cells: Donor variability and response to inflammatory stimuli. Cytokine 50: 317-321.

\section{Discussion with Reviewers}

Reviewer I: It would be of interest to know whether the cells that migrated towards the SDF-1 releasing material were actually found also at the material itself after longer times of culture. Did the authors investigate this as well? Authors: We did not investigate that. The Ch/PGA PEMs are stable at $\mathrm{pH}$ 5, but disrupt at $\mathrm{pH} 7.4$ and release SDF-1. Therefore, these materials do not maintain their structure after several days under cell culture conditions.

Reviewer II: The use of the thickness of the polyelectrolyte multilayers (PEM) as a measure to conclude that the SDF-1 to chitosan interaction hindered the polyelectroyte complex formation, is insufficient. How is it established that SDF1 when incorporated within the chitosan solution had no observed interaction, so that no reduction in thickness was observed?

Authors: In a previous study (Antunes et al., 2011, text reference), PEMs were extensively characterised by different techniques and thickness of the complexes correlated very well with other techniques. SDF-1 interaction with the complexes did not seem to affect the PEMs thickness due to its small size (MW of $8 \mathrm{kDA}$ ) and low concentration (100 to $500 \mathrm{ng} / \mathrm{mL}$ ) compared with the polymers used. The MW of Ch and PGA are in the range of $300 \mathrm{kDa}$ and 10-50 kDa, respectively, and the substances are used in higher concentrations $(0.2 \mathrm{mg} / \mathrm{mL})$. Thus, the 
introduction of SDF-1 does not affect the thickness of the complexes. On the contrary, when $\mathrm{Ch} / \mathrm{PGA}$ interaction is affected, disruption can easily be found by thickness measurements, since $\mathrm{Ch}$ and PGA are large molecules.

Reviewer II: Please provide figures for the PEM platforms. Authors: The PEMs are nano-sized films, therefore their macroscopic aspect reveals only the substrates used to PEMs buildup (gold or glass). In previous studies (Antunes et al., 2011, text reference), images of these complexes were acquired using atomic force microscopy.

Reviewer II: The figure showing the different incorporation strategies versus the SDF-1 concentration is not clear. SDF1 loaded on the PEM after chitosan retains more SDF-1, which could be ideal for use, but this has not been followed up in the release study to assess the stability.

Authors: The SDF-1 release studies were only carried out in PEMs in which $\mathrm{Ch}$ and PGA interaction was not affected, to guarantee the presence of the multi-layered structure. Since when SDF-1 is introduced after $\mathrm{Ch}$, the complex thickness dramatically decreases, suggesting that the complexes were not formed. Hence, this strategy was not used to study the release kinetics of this chemokine.
Reviewer II: The release study could have been carried out till no detectable level of SDF-1 is measured. Please comment.

Authors: The release studies were limited by the techniques used: by radiolabelling, the protein and radioactive iodine may not be bound for long periods of time, and free iodine $\left.{ }^{125} \mathrm{I}\right)$ might adsorb to the substrates, masking the results obtained. Also, the minimum detectable dose of the SDF-1 ELISA kit (R\&D Systems) is $18 \mathrm{pg} / \mathrm{mL}$, which is close to the lowest values detected in our test ( 17 to $42 \mathrm{pg} / \mathrm{mL}$ ).

Reviewer III: The advantage of using such a protein delivery system is not clear. No comparison with any existing protein delivery system is performed. Please comment.

Authors: We agree with the reviewer that this aspect is fundamental. Other strategies might have been used and the literature presents many possibilities to deliver growth factors. The relevance of studying such a wide range of strategies would be totally justified in vivo and certainly we would test extensively some of those strategies. However, the purpose of this investigation was to explore the feasibility of incorporating SDF-1 in ultra-thin films, at the molecular level. The relevance of this technology has been recently demonstrated by other studies (see Discussion). 